\title{
Mining Co-expression Graphs: Applications to MicroRNA Regulation and Disease Analysis
}

\author{
Malay Bhattacharyya \\ Senior Research Fellow \\ MIU, Indian Statistical Institute, Kolkata, India
}




\section{Some Concepts from Biology}




\section{Biogenesis of Genes and MicroRNAs}

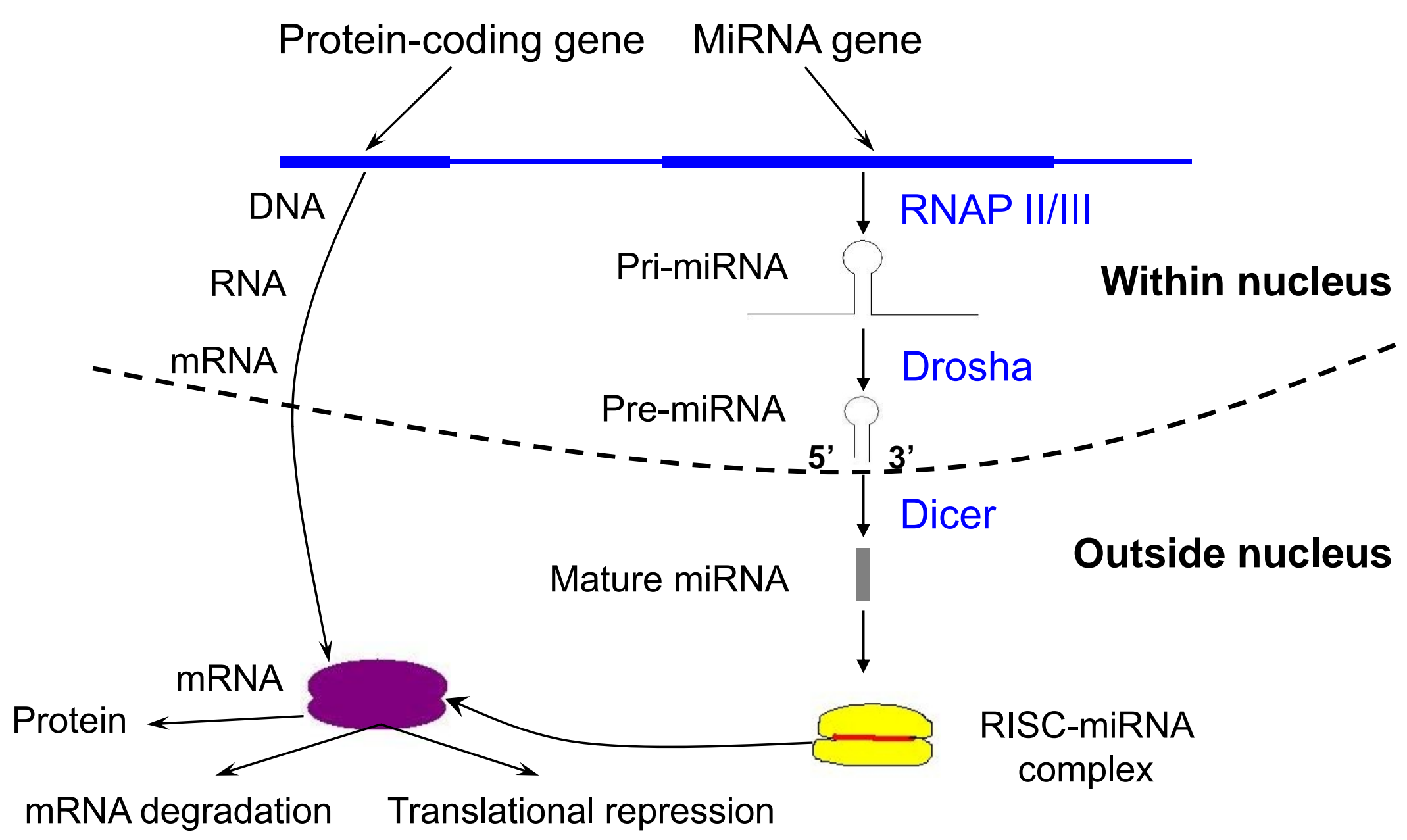




\section{Mapping from Molecules to Systems}

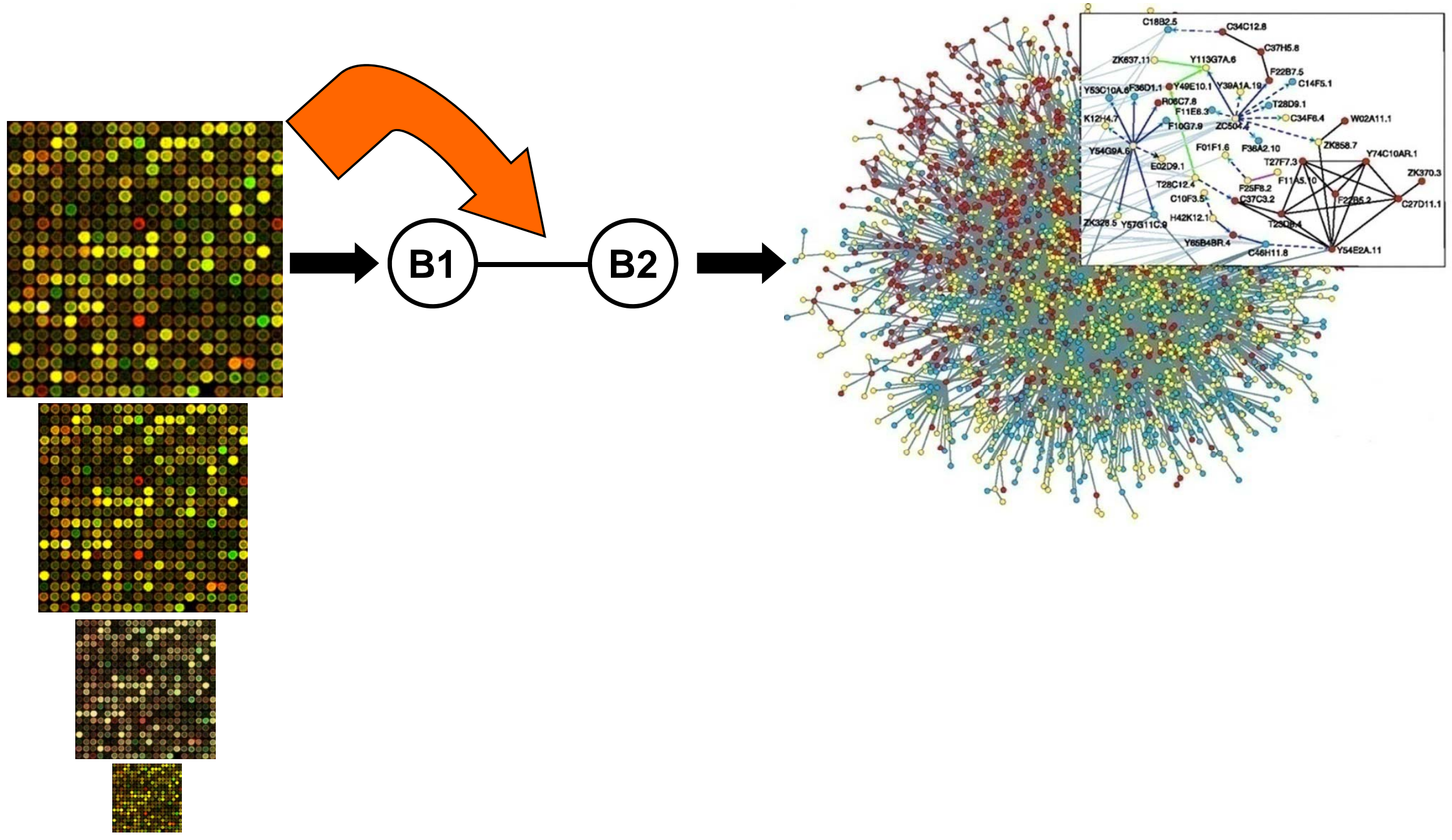




\section{Disease Association of MicroRNAs}

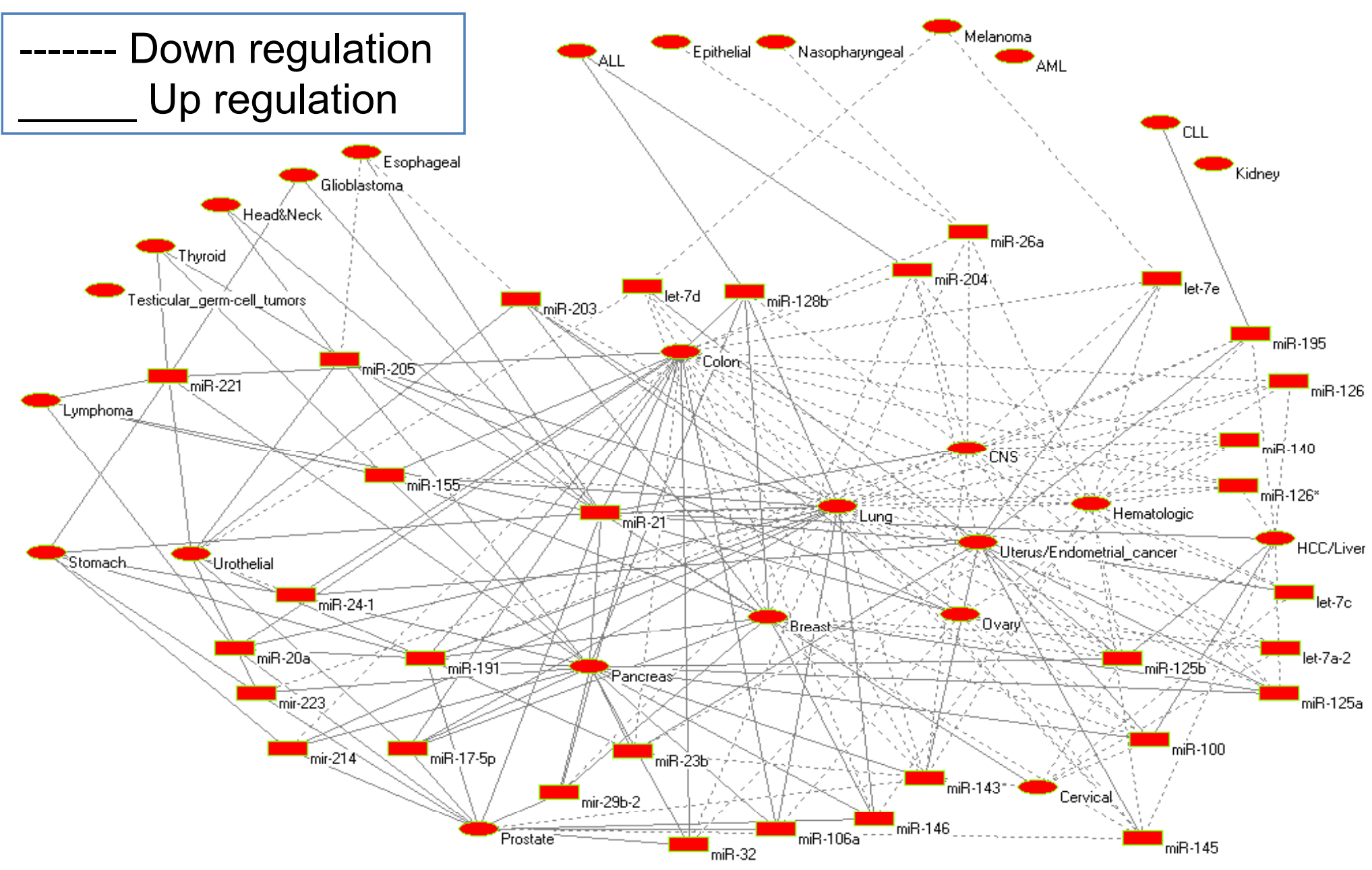




\section{Outline of the Talk}

- Expression studies to co-expression graph construction

- Co-expression graph mining

- Studying the differential co-expression graphs

- Co-expression to coregulation

- Disease analysis

- Future Goals 


\section{Expression Studies to Co- expression Graph Construction}




\section{Co-expression Measures}

\begin{tabular}{|c|c|c|}
\hline Name & Measure & Type \\
\hline \hline Uncentered correlation coefficient/Cosine & $\left(\mathbf{E}_{i} \bullet \mathbf{E}_{j}\right) /\left(\left\|\mathbf{E}_{i}\right\|\left\|\mid \mathbf{E}_{j}\right\|\right)$ & Similarity \\
\hline Pearson correlation coefficient & $\operatorname{Cov}\left(\mathbf{E}_{i}, \mathbf{E}_{j}\right) /\left(\sigma_{\mathbf{E}_{i}} \sigma_{\mathbf{E}_{j}}\right)$ & Similarity \\
\hline Spearman's rank correlation & $\rho\left(\operatorname{Ranked}\left(\mathbf{E}_{i}\right), \operatorname{Ranked}\left(\mathbf{E}_{j}\right)\right)$ & Similarity \\
\hline Cross-correlation 1 & $\left(\frac{1-\rho\left(\mathbf{E}_{i}, \mathbf{E}_{j}\right)}{1+\rho\left(\mathbf{E}_{i}, \mathbf{E}_{j}\right)}\right)$ & Distance \\
\hline Cross-correlation 2 & $\sqrt{2\left(1-\rho\left(\mathbf{E}_{i}, \mathbf{E}_{j}\right)\right)}$ & Distance \\
\hline Root mean square & $\frac{1}{n} \sqrt{|| \mathbf{E}_{i}-\mathbf{E}_{j} \|^{2}}$ & Distance \\
\hline Minkowski & $\sqrt[p]{\| \mathbf{E}_{i}-\mathbf{E}_{j}||^{p}}$ & Distance \\
\hline Squared Euclidean & $\left\|\mathbf{E}_{i}-\mathbf{E}_{j}\right\|^{2}$ & Distance \\
\hline City block/Manhattan & $\left|\mathbf{E}_{i}-\mathbf{E}_{j}\right|$ & Distance \\
\hline Chebyshev & $\max _{t}\left(\left|\mathbf{E}_{i}(t)-\mathbf{E}_{j}(t)\right|\right)$ & Distance \\
\hline Kullback-Leibler & $\sum_{t=1}^{n} e_{j}(t) \ln \frac{e_{j}(t)}{e_{i}(t)}$ & Distance \\
\hline
\end{tabular}

- Very few measures for quantifying positive and negative dependence

- How to signify the amount of deviation? 


\section{Variation of Deviation in Co-expression}

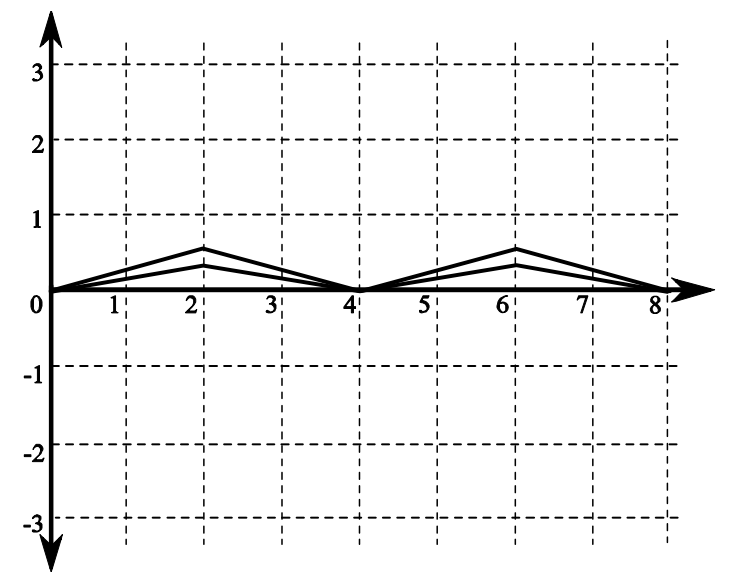

(I)

Modeling both similarity and deviation

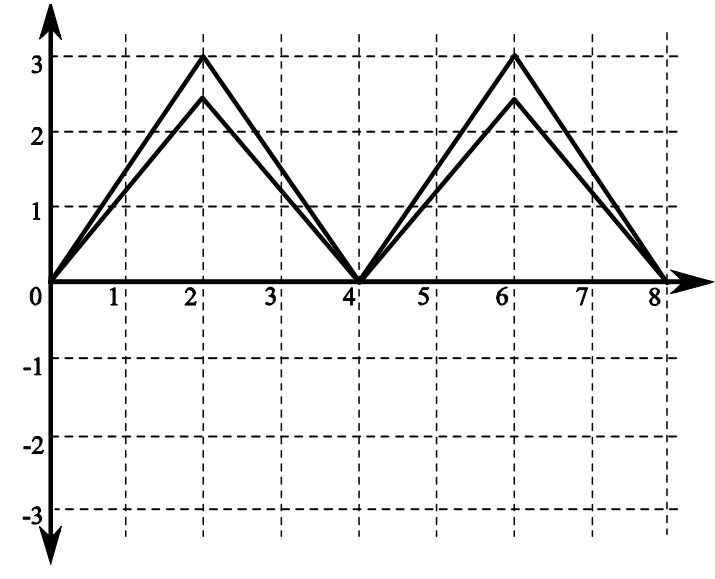

(II)

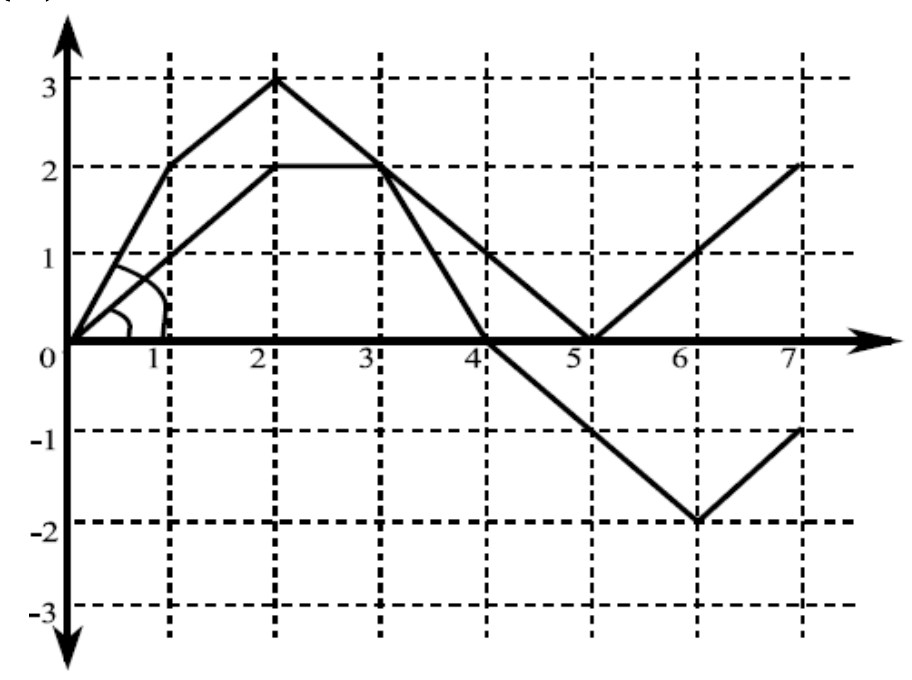




\section{A Novel Measure of Co-expression}

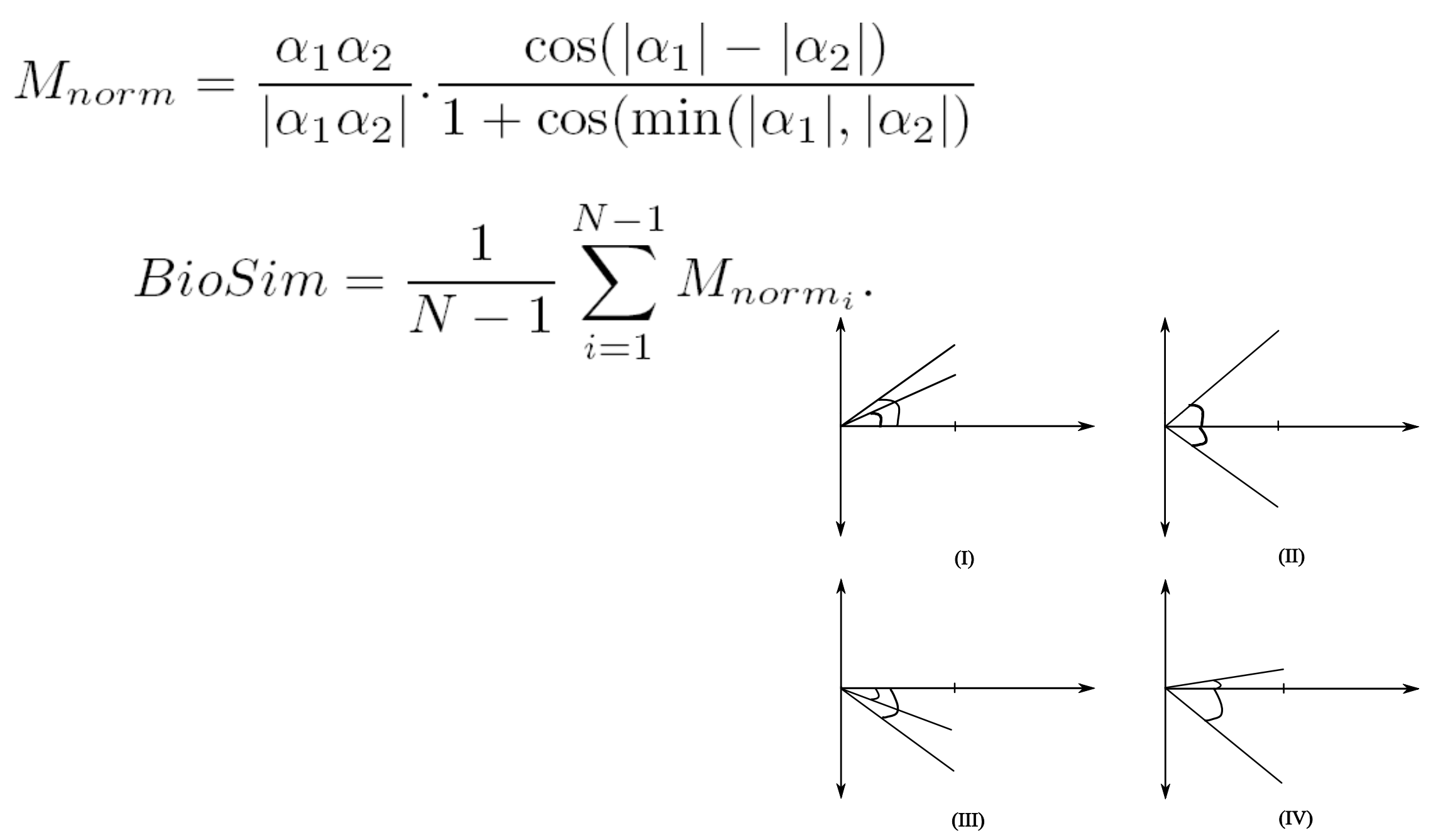




\section{Combining Co-expression Graphs}
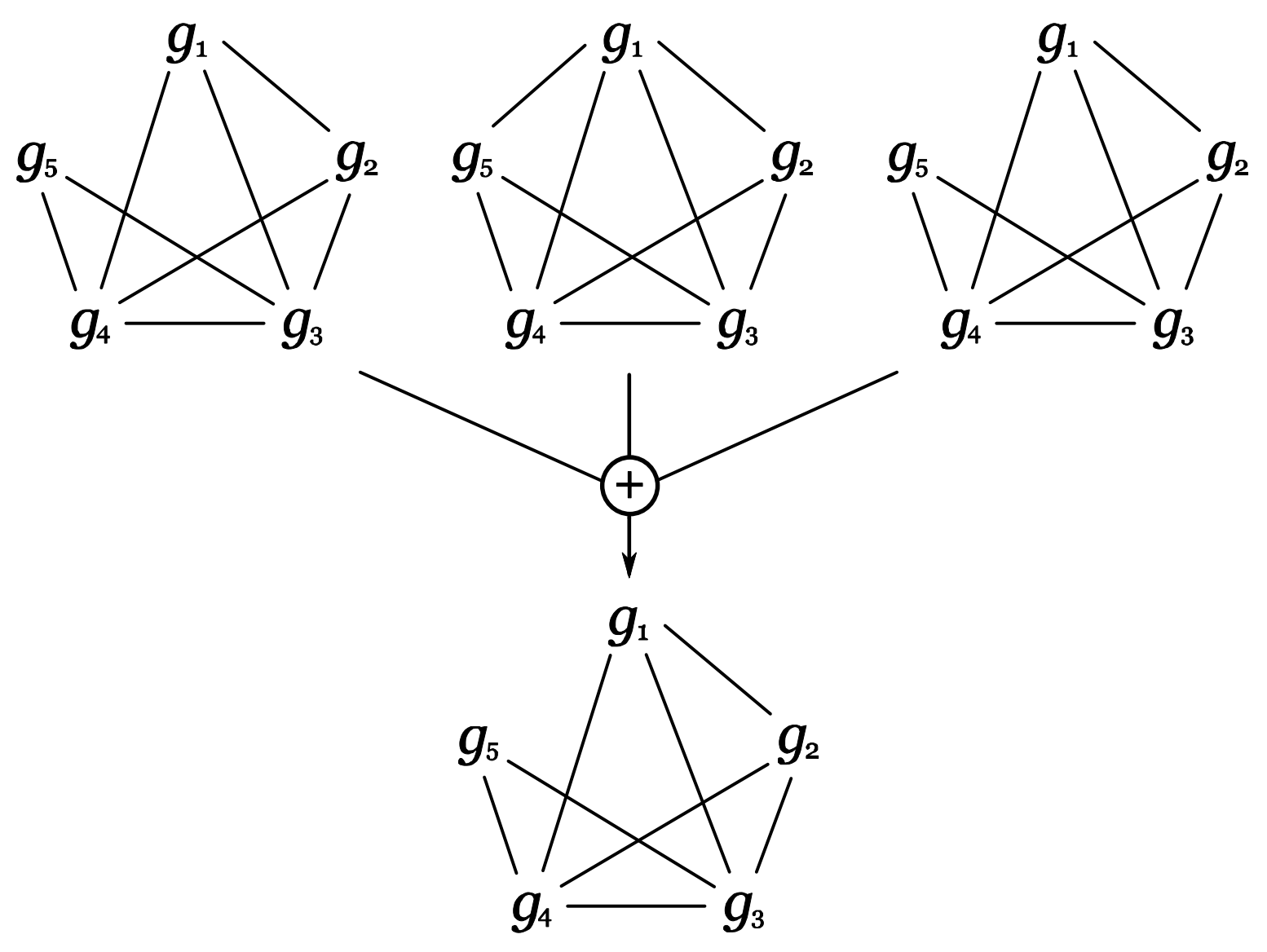


\section{Consensus Gene Co-expression Graph}

$$
\begin{gathered}
N_{1}^{\prime}=\left(N, A, W_{1}\right) \quad N_{2}^{\prime}=\left(N, A, W_{2}\right) \\
S\left(N_{1}^{\prime}, N^{\prime}\right)=\frac{1}{|A|} \sum_{\forall i \in N \forall j \in N, i \neq j} \sum_{i=\mid} 1-\left|W_{1}(i, j)-W_{2}(i, j)\right|
\end{gathered}
$$

A consensus gene co-expression graph, $\boldsymbol{N}_{c}^{\prime}=\left(\boldsymbol{N}, A, W_{c}\right)$, of a set of $n$ graphs $\left\{N_{1}^{\prime}=\left(N, A, W_{1}\right), N_{2}^{\prime}=\left(N, A, W_{2}\right), \ldots, N_{n}^{\prime}=\left(N, A, W_{n}\right)\right\}$, is defined to be a graph for which

$$
\prod_{i=1}^{n} S\left(N_{i}^{\prime}, N_{c}^{\prime}\right) \quad \text { becomes maximum. }
$$

$$
W_{c}(i, j)=\sqrt[\alpha]{\sum_{k=1}^{n} \xi_{k}(i, j) W_{k}(i, j)^{\alpha}} \quad \xi_{k}(i, j)=\frac{\# \text { Condition }_{k}}{\sum_{k=1}^{n} \# \text { Condition }_{k}}
$$




\section{Co-expression Graph Mining}




\section{Co-expression Graph Mining}

- Dense subgraphs in gene co-expression networks based on conventional definition of density

- Requires relaxation in the definition of density

- Significant participation of all the members should be considered

- Quasi-cliques in unweighted graphs

- Dense cores of autonomous systems in communication networks

- What about unweighted graphs?

- CLIQUE-like problems on graphs

- On finding all the dense groups

- study specific to scale-free graphs 


\section{Generation of False DAV}

Density of the graph $=2 \cdot(15+2) /[7 .(7-1)] \sim 0.8$

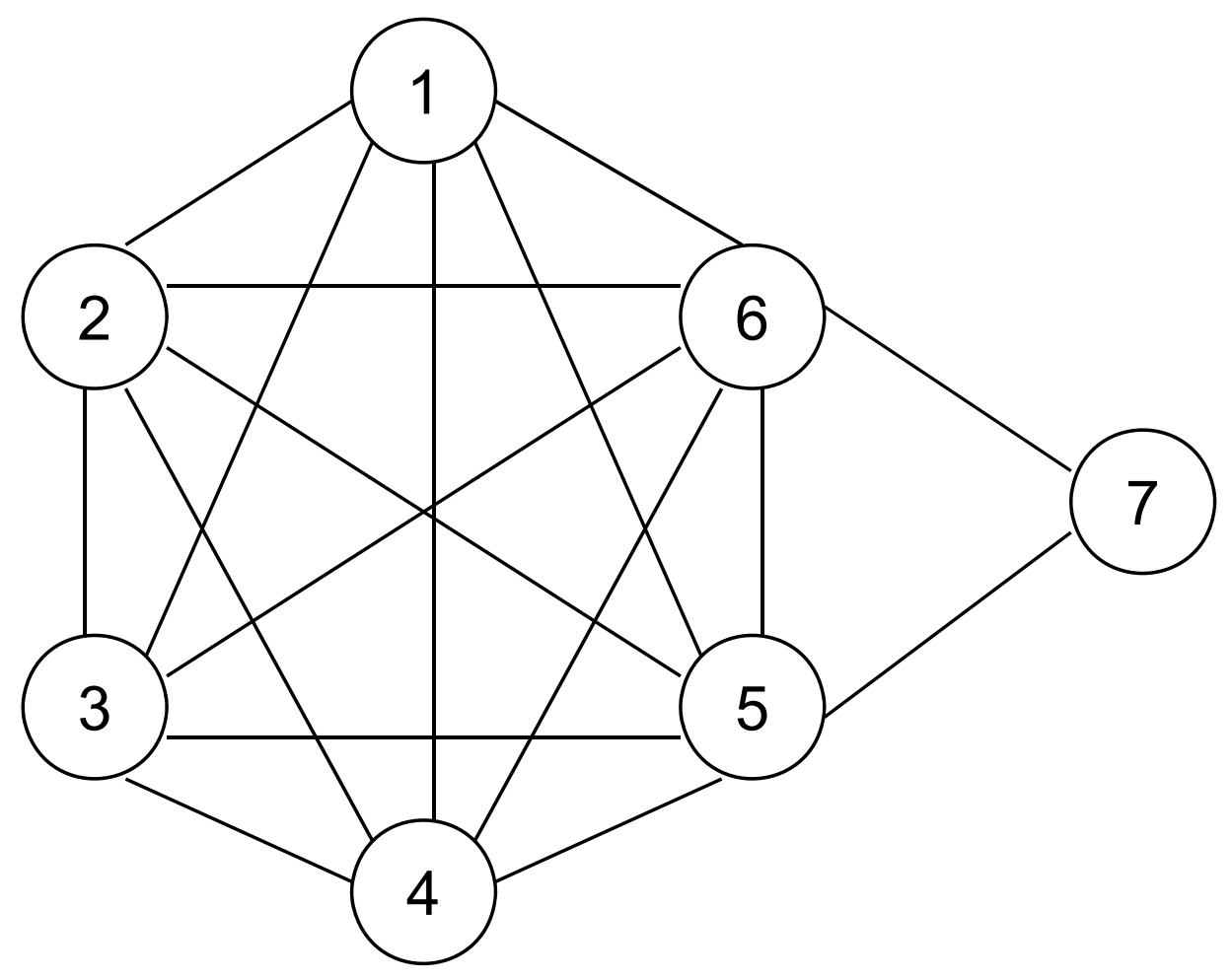

${ }^{*}$ Participation density of 7 is $=2 / 6 \sim 0.3$ 


\section{Statement of MAX-DAV}

Given a weighted graph,

$$
\tilde{G}=(V, \tilde{E}, \Omega)
$$

and an association density threshold of an $\mathrm{N}$-vertexlet $\delta$, locate a dense $\mathrm{N}$-vertexlet,

$$
V_{\text {let }}^{N} \text { max }
$$

that has the maximum cardinality, i.e.,

$$
N_{\max } \geq N_{i}: \forall \mu_{V_{\text {let }}}^{N_{i}} \geq \delta, \forall N_{i}=\{1,2, \ldots,|V|\}
$$




\section{Scale-free Graphs}

- Degree distribution

$$
\boldsymbol{P}(\boldsymbol{k}) \sim \boldsymbol{k}^{-\gamma} ; \boldsymbol{\gamma}>\mathbf{0}
$$
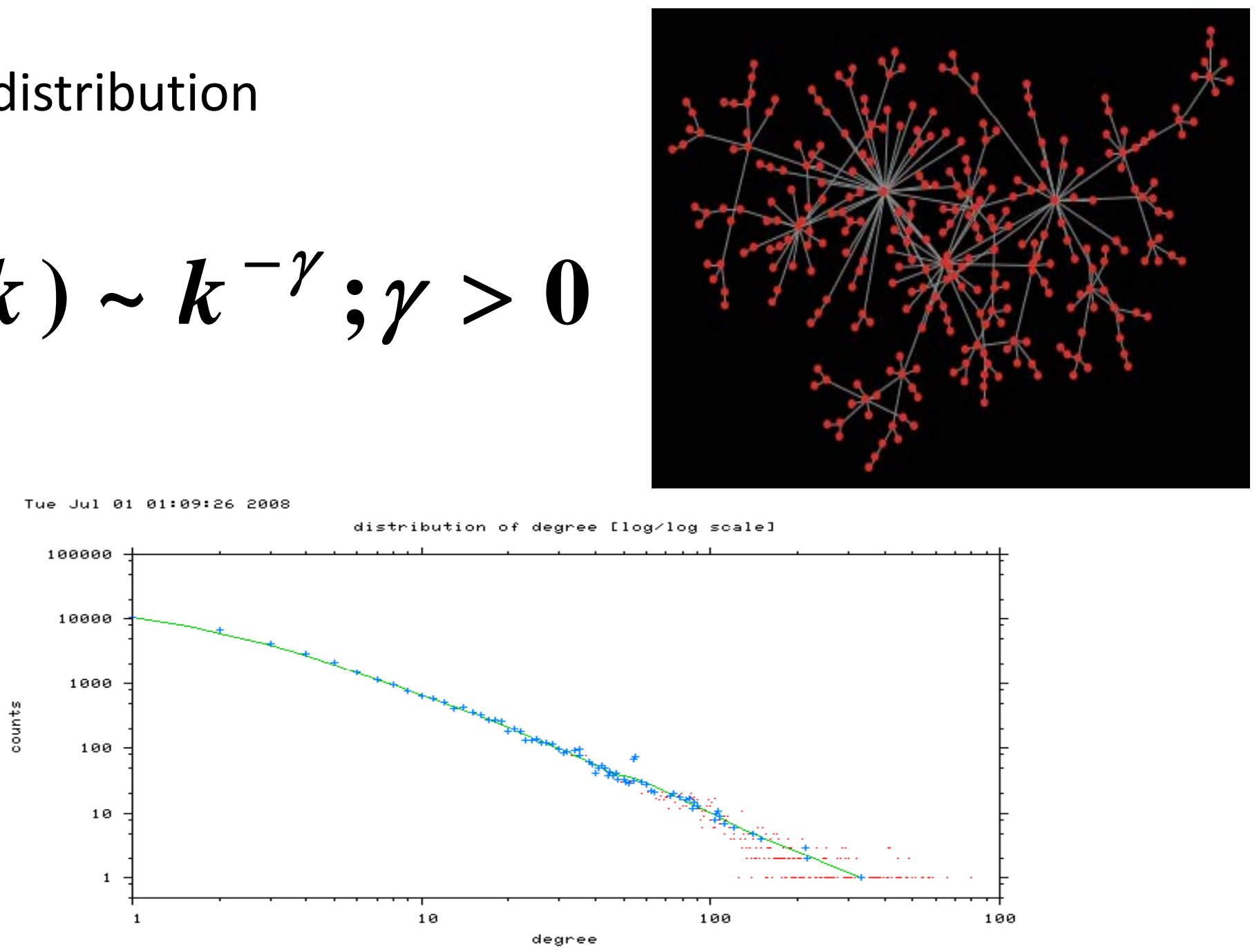


\section{Equivalence with Quadratic 0-1 Programming Problem}

> Theorem 3: The MAX-DAV in a weighted graph,

$$
\tilde{G}=(V, \tilde{E}, \Omega)
$$

for a given association density threshold $\delta$, is equivalent to the following optimization problem,

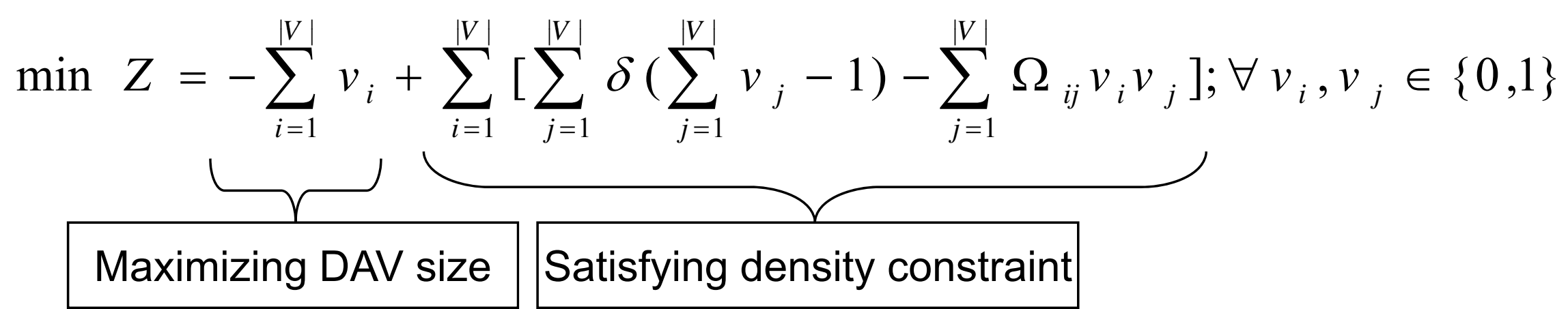

where, $v_{i}=1$, if $x_{i}$ is in the maximum DAV, else $v_{i}=0, \forall \boldsymbol{x}_{\boldsymbol{i}} \in \boldsymbol{V}$. 


\section{Schematic Diagram of the Maximum Neural Network Model}

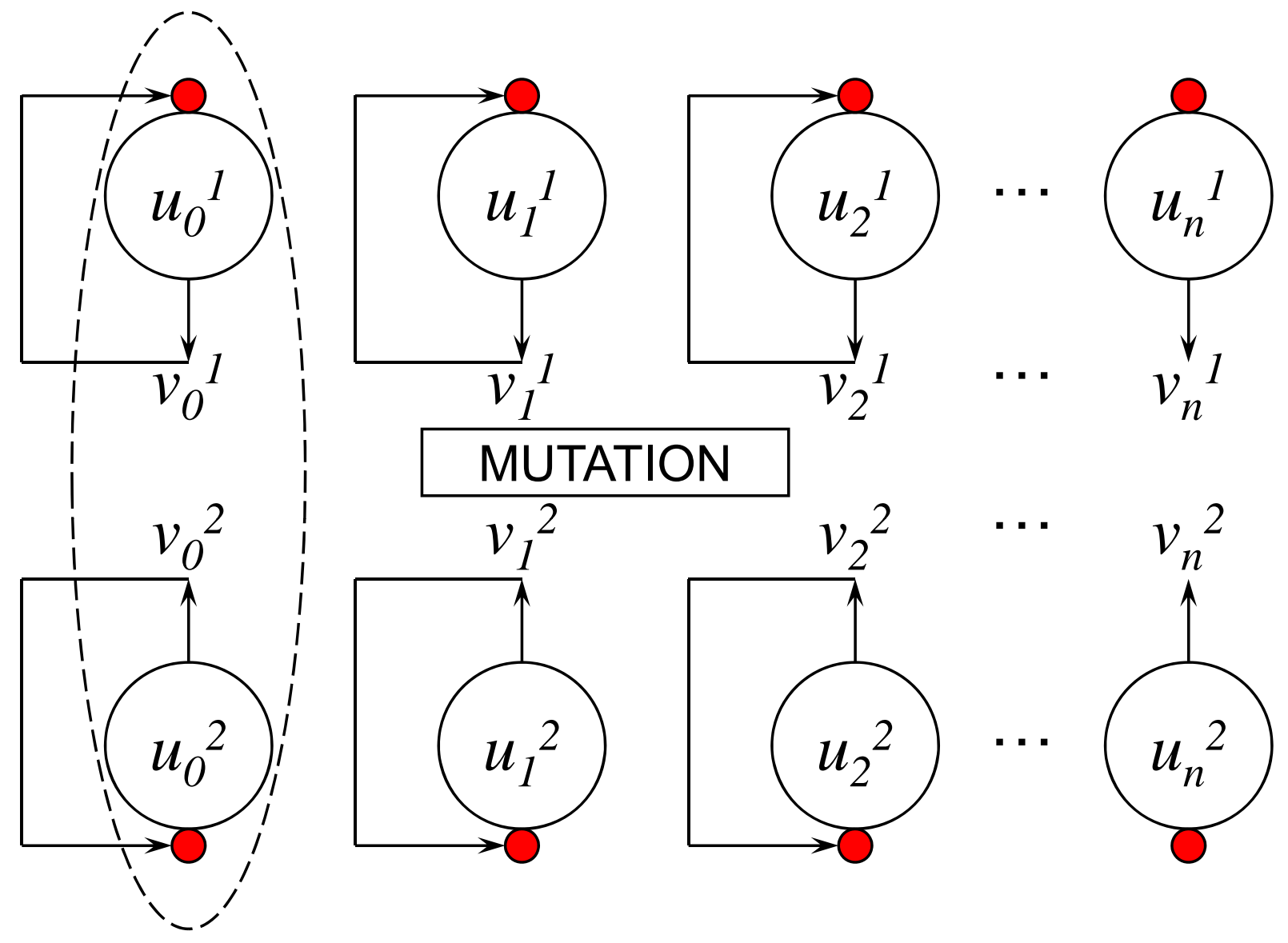




\section{Co-expression to Coregulation}




\section{Analysis of MicroRNA Regulation}

- Mostly biological analysis

- Not for an exhaustive collection of miRNAs ( $<10 \%)$

- No significant computational analysis based on expression profiling

- Sequence-based analyses based on the construction of positional weight matrices

- How to establish a correspondence between co-expression, cofunctionality and co-regulation? 


\section{Studies on miRNAs (Schizophrenia Dataset)}

\begin{tabular}{cccccc}
\hline$t$ & $\delta_{t}$ & Module size & $S E$ & $\sum S E$ & $S I_{C / V}$ \\
\hline 0 & 1 & - & - & - & - \\
$\ldots$ & $\ldots$ & - & - & - & - \\
3 & 0.9850 & 13 & 0.18 & 70.32 & 0.9966 \\
4 & 0.9802 & 8 & 0.23 & 69.79 & 0.9953 \\
5 & 0.9752 & 26 & 0.49 & 72.71 & 0.9913 \\
6 & 0.9704 & 15 & 0.69 & 71.89 & 0.9857 \\
7 & 0.9655 & 4 & 0.85 & 70.25 & 0.9758 \\
8 & 0.9607 & 14 & 1.25 & 72.51 & 0.9729 \\
9 & 0.9559 & 25 & 1.22 & 72.86 & 0.9786 \\
10 & 0.9511 & 6 & 1.37 & 64.76 & 0.9904 \\
\hline
\end{tabular}




\section{Biological and Statistical Validation}

\begin{tabular}{|c|c|c|c|}
\hline Priority modules & Schizophrenia dataset & Tissue-specific dataset & Stem cell dataset \\
\hline$P M 1$ & 589 & 1074 & 1585 \\
\hline$P M 2$ & 51 & 235 & 148 \\
\hline$P M 3$ & 81 & 0 & 211 \\
\hline$P M 4$ & 260 & 291 & 2 \\
\hline$P M 5$ & 0 & 12 & 8 \\
\hline$P M 6$ & 13 & 40 & 30 \\
\hline$P M 7$ & 1 & 20 & 110 \\
\hline$P M 8$ & 24 & 64 & 13 \\
\hline$P M 9$ & - & - & 0 \\
\hline$P M 10$ & - & - & 0 \\
\hline$P M 11$ & - & - & 13 \\
\hline$P M 12$ & - & - & 0 \\
\hline \multirow[t]{5}{*}{$P M 13$} & - & - & 73 \\
\hline & Dataset & p-value & \\
\hline & Schizophrenia & $<1 E-4$ & \\
\hline & Tissue-specific & $<1 E-4$ & \\
\hline & Stem cell & $<1 E-4$ & \\
\hline
\end{tabular}




\section{Degree Distribution in TF-microRNA Interaction Graph}
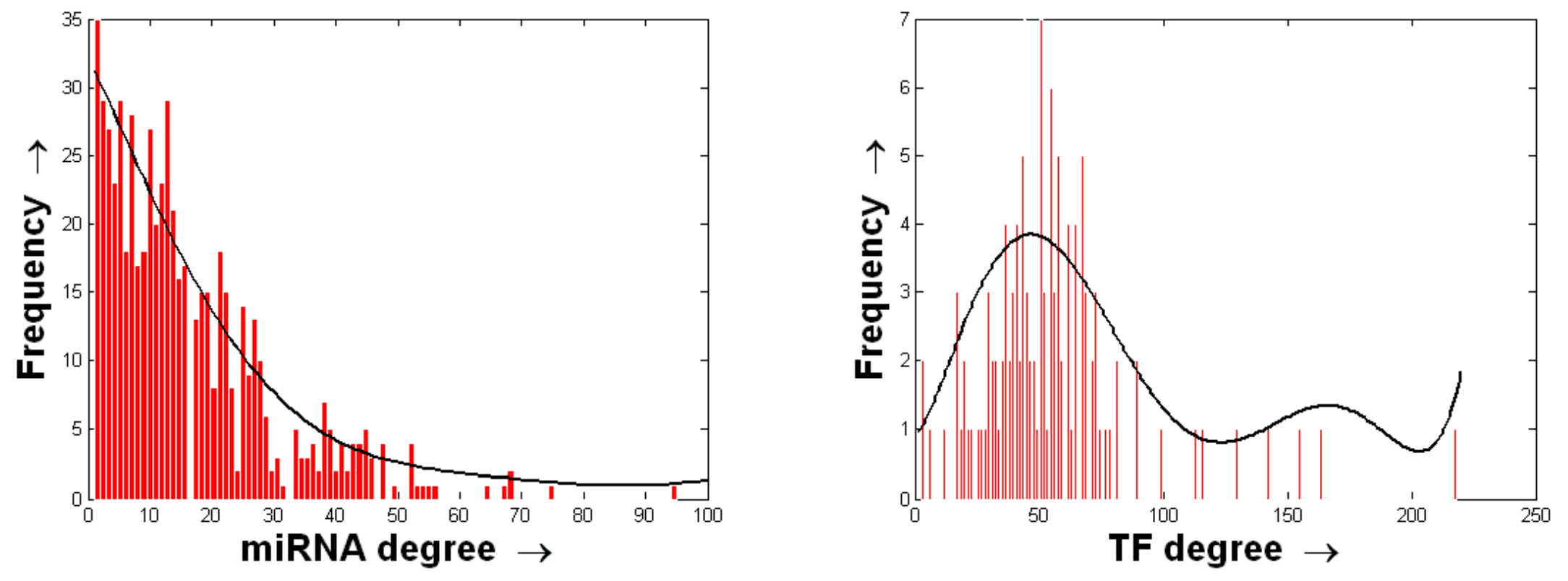


\section{Studying the Differential Co- expression Graphs}




\section{Relative Co-expression Score}

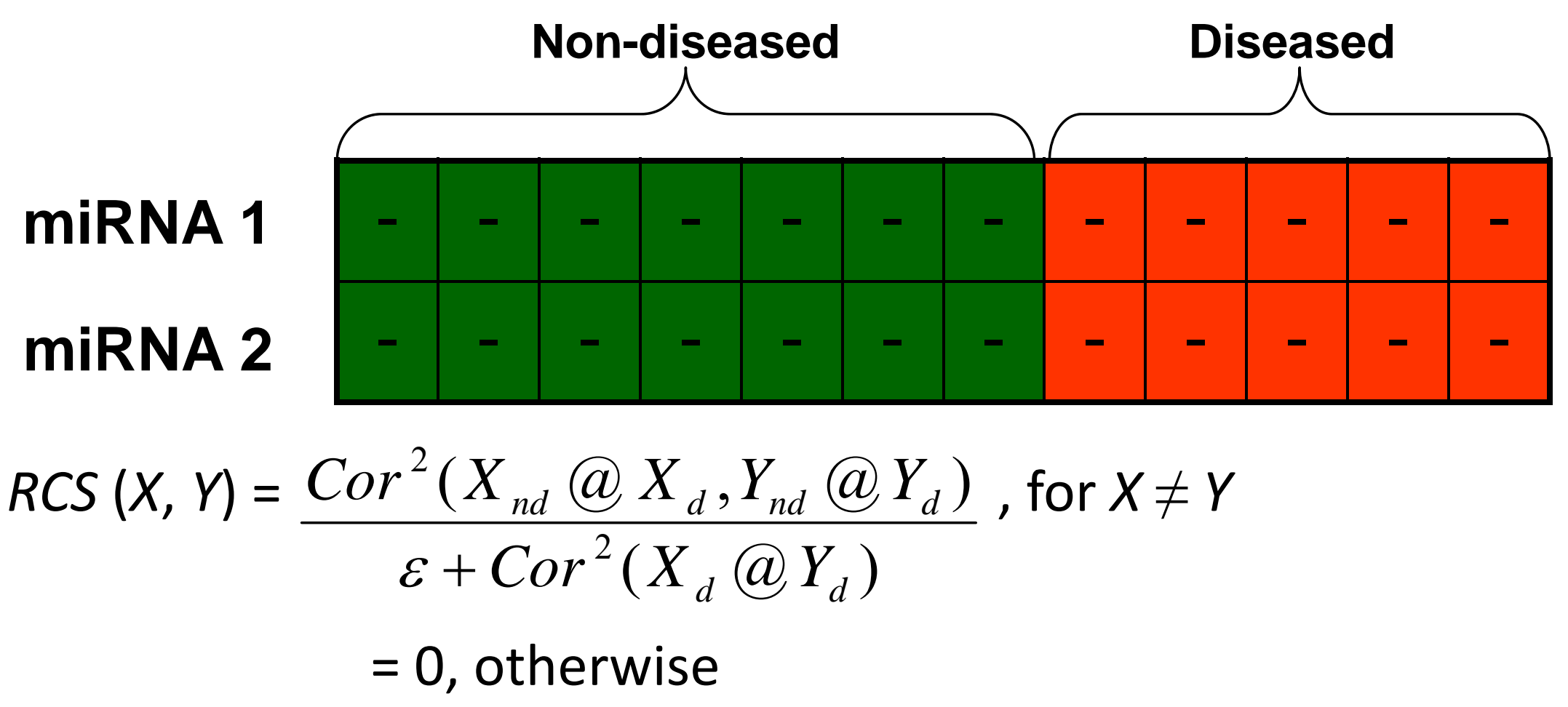

Here, the constant $\varepsilon>0$ is incorporated to map the range of $R C S$ from $[0, \infty]$ to $[0,1 / \varepsilon]$ and $\operatorname{Cor}(X, Y)$ denotes the Pearson correlation coefficient between $X$ and $Y$. 


\section{Association of MicroRNAs with Alzheimer's Disease}

\begin{tabular}{|c|c|c|c|c|c|c|}
\hline $\begin{array}{l}\text { AD related } \\
\text { miRNAs }[32]\end{array}$ & \multicolumn{4}{|c|}{$\begin{array}{c}\text { miRNAs with aberrant expression } \\
\text { in AD brains }[25]\end{array}$} & $\begin{array}{l}\text { AD related } \\
\text { miRNAs }[20]\end{array}$ & $\begin{array}{l}\text { Brain-specific } \\
\text { miRNAs }[20]\end{array}$ \\
\hline miR124 & miR-9 & miR-21 & miR100 & miR-425 & miR107 & miR-661 \\
\hline $\operatorname{miR} 125 \mathrm{~b}$ & $\operatorname{miR} 128$ & miR-222 & miR-212 & miR-30e-5p & miR-29a & mir-09369 \\
\hline miR103 & $\operatorname{miR} 146 a$ & miR-91 & miR-363 & miR-92 & miR-29b1 & $\operatorname{mir} 15903$ \\
\hline miR107 & miR146b & miR-9-2 & $\operatorname{miR} 125 \mathrm{~b}$ & miR-200c & miR106b & mir-44691 \\
\hline $\operatorname{miR} 15 \mathrm{a}$ & miR-29a/b1 & miR-92b & miR-511 & miR-423 & miR146a & miR-325 \\
\hline $\operatorname{miR} 15 \mathrm{~b}$ & miR15a & miR-9-3 & miR-320 & miR-30c & miR17 & miR-506 \\
\hline miR16 & miR-27a & miR-34a & miR-27b & $\operatorname{miR} 18 b$ & miR-20a & miR-515-3p \\
\hline miR195 & $\operatorname{miR} 19 b$ & miR-326 & miR-34a & miR-615 & miR-21 & miR-612 \\
\hline miR-424 & let-7i & miR1291 & miR145 & miR-629 & & miR-768-3p \\
\hline $\operatorname{miR} 128$ & miR101 & miR129-2 & miR148a & miR-637 & & mir-06164 \\
\hline miR-29a & miR106b & miR136 & miR-381 & miR-657 & & mir-32339 \\
\hline miR-29b & miR-22 & miR181c & $\operatorname{miR}-422 \mathrm{a}$ & & & mir- 45496 \\
\hline miR-29c & miR-26a & miR197 & miR-98 & & & miR107 \\
\hline miR-214 & miR-26b & miR-210 & $\operatorname{miR} 132$ & & & miR-93 \\
\hline
\end{tabular}




\section{Differential Co-expression Analyses}

\begin{tabular}{|c|c|c|c|c|}
\hline \multirow{2}{*}{ Method } & \multicolumn{2}{|c|}{ Gray Matter } & \multicolumn{2}{c|}{ White Matter } \\
\cline { 2 - 5 } & $\begin{array}{c}\text { \# AD related } \\
\text { microRNAs }\end{array}$ & $p$-value & $\begin{array}{c}\text { \# AD related } \\
\text { microRNAs }\end{array}$ & $p$-value \\
\hline $\begin{array}{c}\text { Student's paired t- } \\
\text { test }\end{array}$ & $8(15)$ & $3.74 \mathrm{E}-02$ & $4(15)$ & $6.96 \mathrm{E}-01$ \\
\hline SAM & $5(15)$ & $4.66 \mathrm{E}-01$ & $3(15)$ & $8.77 \mathrm{E}-01$ \\
\hline
\end{tabular}

* Among the top 15 microRNAs selected by the respective analysis

\begin{tabular}{|c|c|c|c|c|}
\hline \multirow{2}{*}{ Method } & \multicolumn{2}{|c|}{ No constraint } & \multicolumn{2}{c|}{ Excluding miR-423-5p } \\
\hline & $\begin{array}{c}\text { \# AD related } \\
\text { microRNAs }\end{array}$ & $p$-value & $\begin{array}{c}\text { \# AD related } \\
\text { microRNAs }\end{array}$ & $p$-value \\
\hline $\begin{array}{c}\text { Correlation-based } \\
\text { analysis }\end{array}$ & $11(16)$ & $7.44 \mathrm{E}-04$ & $5(17)$ & $4.66 \mathrm{E}-01$ \\
\hline
\end{tabular}

* Among the top 15 pairs of microRNAs selected by the respective analysis 


\section{Comparative Studies on Different Graph Clustering Algorithms}

\begin{tabular}{|c|c|c|c|c|c|c|}
\hline \multirow{2}{*}{ Cluster No. } & \multicolumn{2}{|c|}{ grPartition } & \multicolumn{2}{c|}{ grPartition with GTOM } & \multicolumn{2}{c|}{ LinLogLayout } \\
\cline { 2 - 7 } & CC & BC & CC & BC & CC & BC \\
\hline \hline 1 & 0.1333 & 0.16667 & 0 & 0.4545 & 0.22414 & 0.0883 \\
2 & 0.1732 & 0.22727 & 0 & 0.375 & 0.11579 & 0.404 \\
3 & 0 & 0.71428 & 0 & 0 & 0.21875 & 0.3629 \\
4 & 0 & 0.33333 & 0.0074 & 0.2353 & 0.21429 & 0.2917 \\
5 & 0 & 0 & 0.0019 & 0.3043 & 0.16667 & 0.3333 \\
6 & 0 & 0.55556 & 0 & 0.0769 & & \\
7 & 0 & 0.6 & 0 & 0.1875 & & \\
8 & 0 & 0.125 & 0.6667 & 1 & & \\
9 & 0.2532 & 0.3 & 0 & 0.1818 & & \\
10 & 0.1667 & 0.25 & 1 & 0.5 & & \\
\hline
\end{tabular}




\section{Whether Differential Co-expression Patterns Do Exist within a Module?}
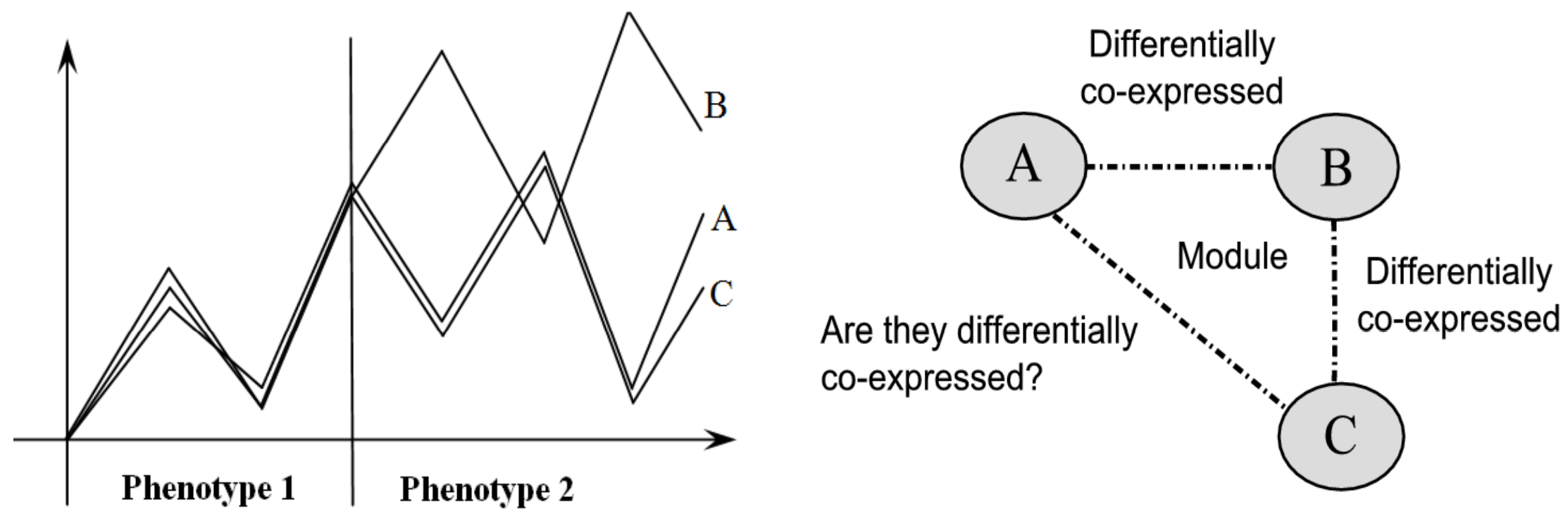


\section{The Proposed Approach}

Input: A differentially co-expressed graph $G=(V, E, W, S)$, a strict lower threshold of differential co-expression value $T$, and a degree threshold TD.

Output: The set of largest DCSTs.

Remove the edges having weight $W \leq T$.

repeat

Remove the nodes from the reduced graph having no connectivity with the others.

repeat

Find the edge having the strongest weight (seed edge) and initialize it as a DCST.

Find the switching pattern of the seed edge.

Find the nodes $s_{i}$ forming the strongest edges with the nodes $i$ in the DCST such that none of them is present in the DCST. Find the degree values of the $s_{i}^{\prime}$ s.

Select the node $s_{i}$ to expand the DCST further by the inclusion of the edge $\left(i, s_{i}\right)$ such that it possesses:

a. comparatively higher weight than the other edges.

b. degree value greater than TD.

c. same switching pattern as that of the seed edge.

Resolve the conflicts in 7.a by randomization.

until The current DCST is no more expandable by the inclusion of edges

if the DCST is empty then

Exit.

else

end if

Return the current DCST and remove its belonging nodes from the original graph $G$.

until The reduced graph is empty 


\section{Construction of the Differentially Co- expressed Switching Tree}

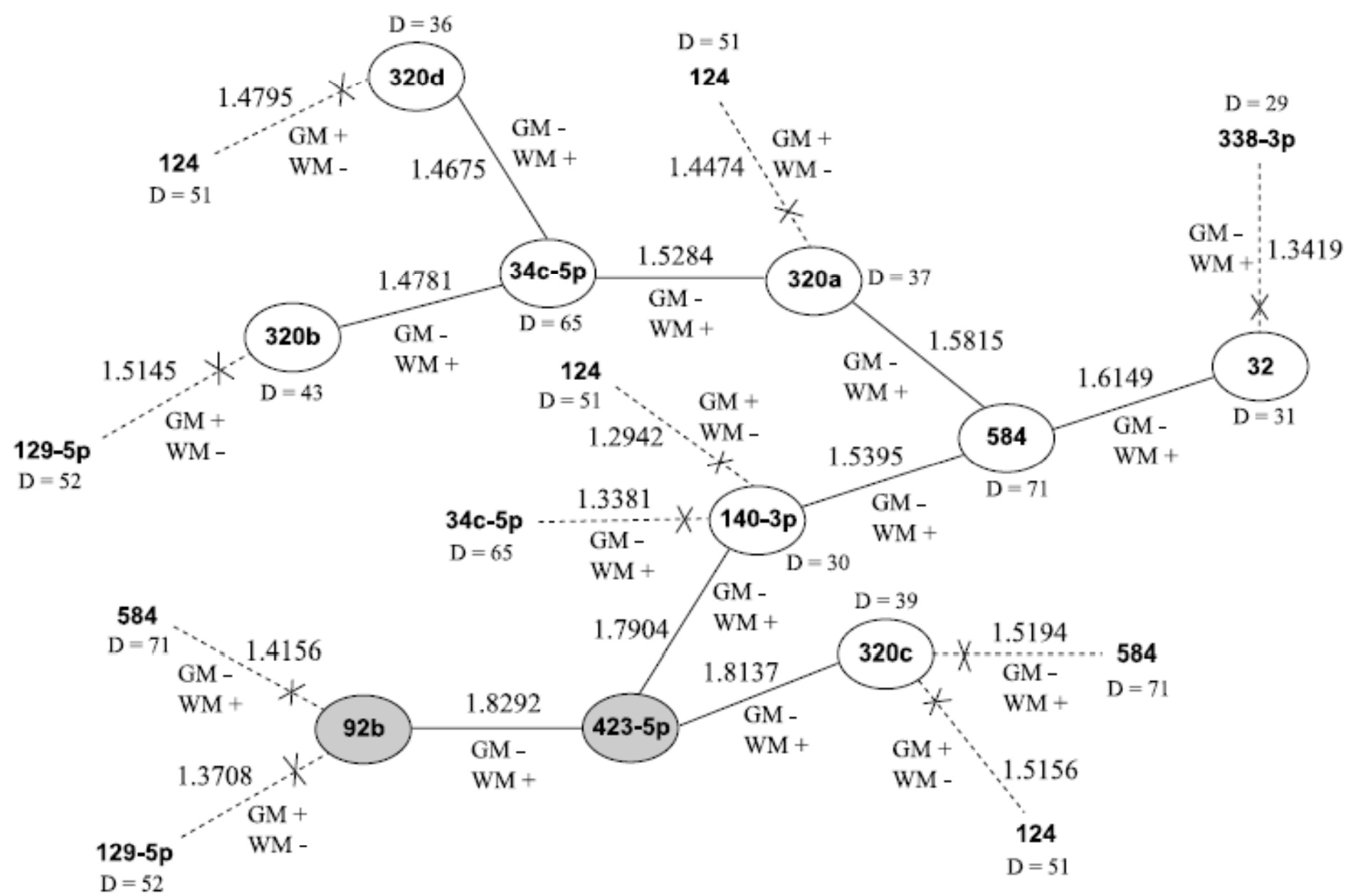


Frequency Distribution of the Degree Values of MicroRNAs

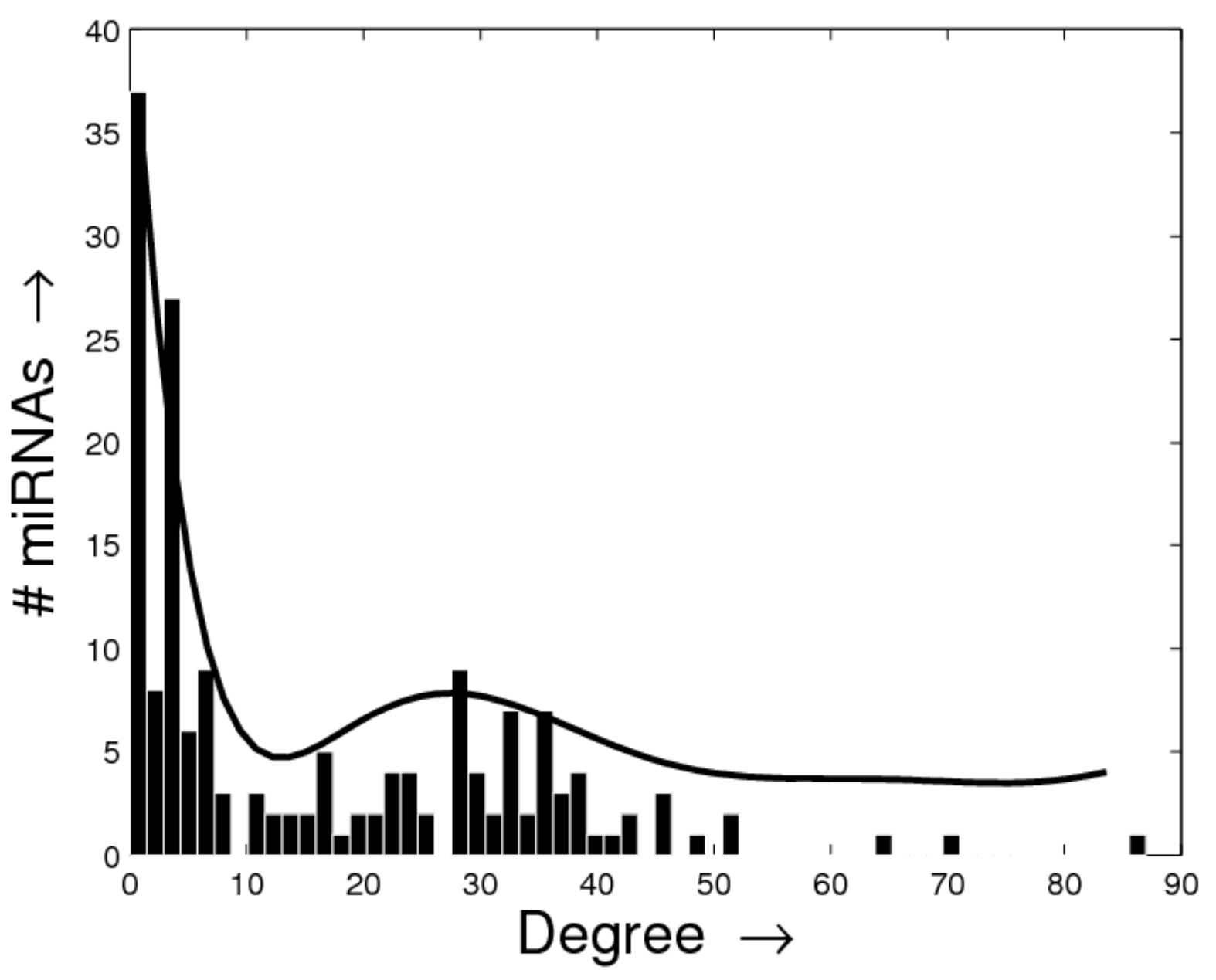




\section{Disease Analysis}




\section{Disease Analysis}

- Differential expression pattern analysis based on different phenotypes and mostly biological

- How to define co-expression/differential co-expression/co-expression dynamics

- Network based analysis

- System level analyses are problem-specific 


\section{HIV-1-Human Protein Interaction Network}

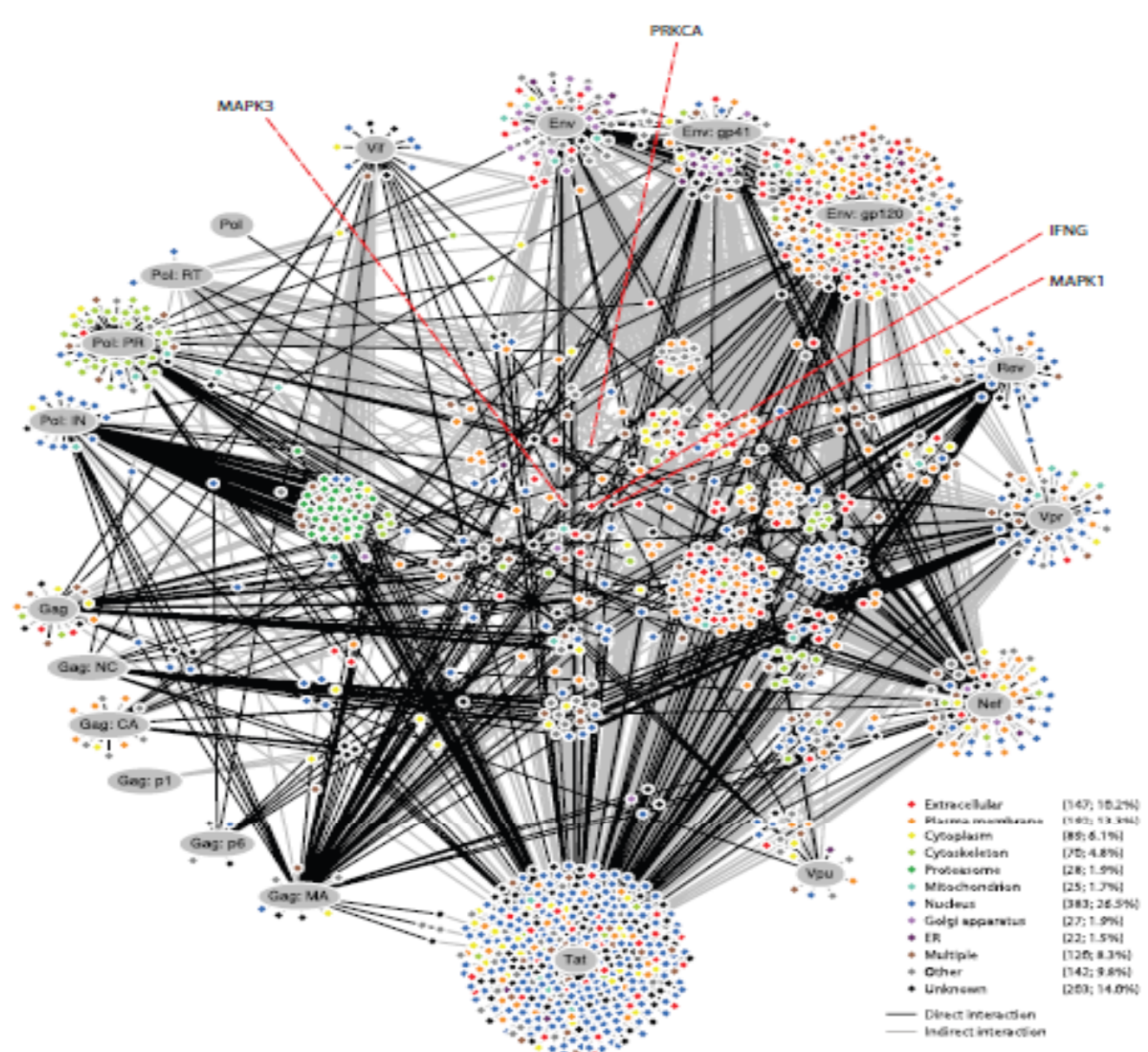

Ptak et al., AIDS Res Hum Retroviruses, 24(12):1497-502, 2008 


\section{Biclustering Approaches}

\begin{tabular}{|c|c|c|c|}
\hline $\mathrm{A}$ & $\mathrm{A}$ & $\mathrm{A}$ & $\mathrm{A}$ \\
\hline $\mathrm{A}$ & $\mathrm{A}$ & $\mathrm{A}$ & $\mathrm{A}$ \\
\hline $\mathrm{A}$ & $\mathrm{A}$ & $\mathrm{A}$ & $\mathrm{A}$ \\
\hline $\mathrm{A}$ & $\mathrm{A}$ & $\mathrm{A}$ & $\mathrm{A}$ \\
\hline
\end{tabular}

(a)

\begin{tabular}{|c|c|c|c|}
\hline A & A & A & A \\
\hline B & B & B & B \\
\hline C & C & C & C \\
\hline D & D & D & D \\
\hline
\end{tabular}

(b)

\begin{tabular}{|c|c|c|c|}
\hline$A$ & $A+a$ & $A+b$ & $A+c$ \\
\hline$A+p$ & $A+p+a$ & $A+p+b$ & $A+p+c$ \\
\hline$A+q$ & $A+q+a$ & $A+q+b$ & $A+q+c$ \\
\hline$A+r$ & $A+r+a$ & $A+r+b$ & $A+r+c$ \\
\hline
\end{tabular}

(c)

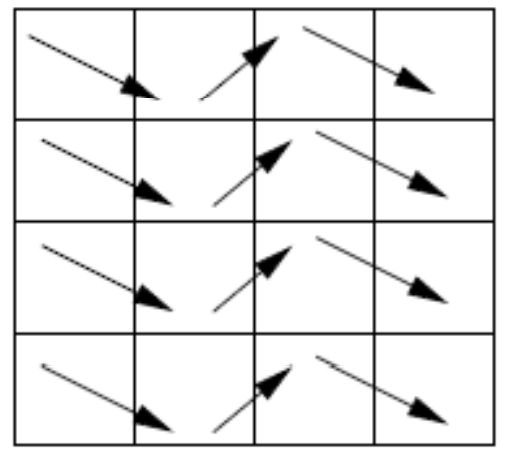

(d)

- Biclustering approaches

- Cheng and Church's algorithm (CCA), SAMBA, Co-clustering algorithm (CA), Divide-and-conquer based algorithm (DBA)

- Bicluster types - fixed value (CCA, SAMBA, CA, DA), fixed row/column (CCA), additive coherent value, and coherent evolution

- Some are able to find overlapping biclusters (CCA, CA) 


\section{Directed Bipartite Graph}

If $V 1, V 2$ are two distinct sets of vertices and $E$ is a subset of $V 1 \times V 2$ then a directed bipartite graph is definable as

$$
G=(V 1, V 2, E)
$$

where the edges $(i, j)$ and $(j, i)$ in $E$ are distinct.

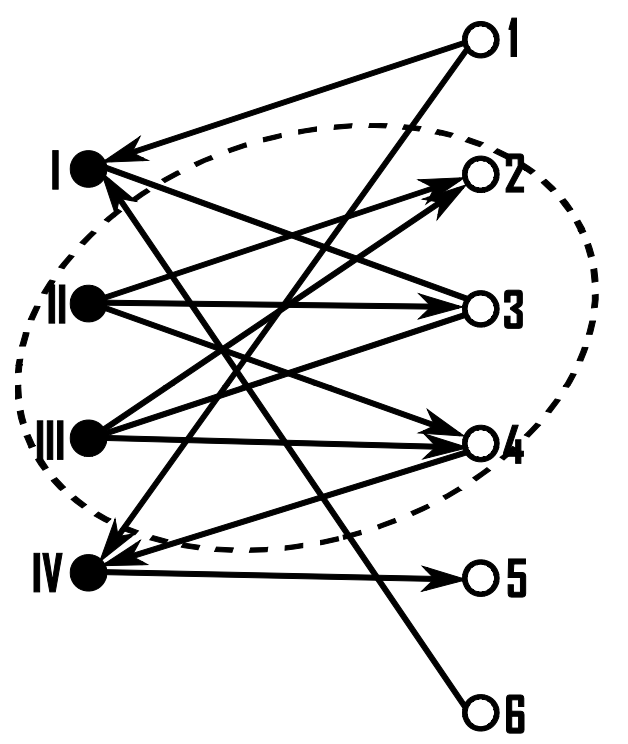

Definition 1 (DBClique). A DBClique is a fully connected subgraph $G^{\prime}=$ $\left(V_{1}^{\prime}, V_{2}^{\prime}, E^{\prime}\right) \subseteq G$ of a directed bipartite graph $G$ such that either $i \in V_{1}^{\prime}, j \in$ $V_{2}^{\prime}, \forall(i, j) \in E^{\prime}$ or $i \in V_{2}^{\prime}, j \in V_{1}^{\prime}, \forall(i, j) \in E^{\prime}$. 


\section{Correspondence of a DBClique to an Interaction Matrix}

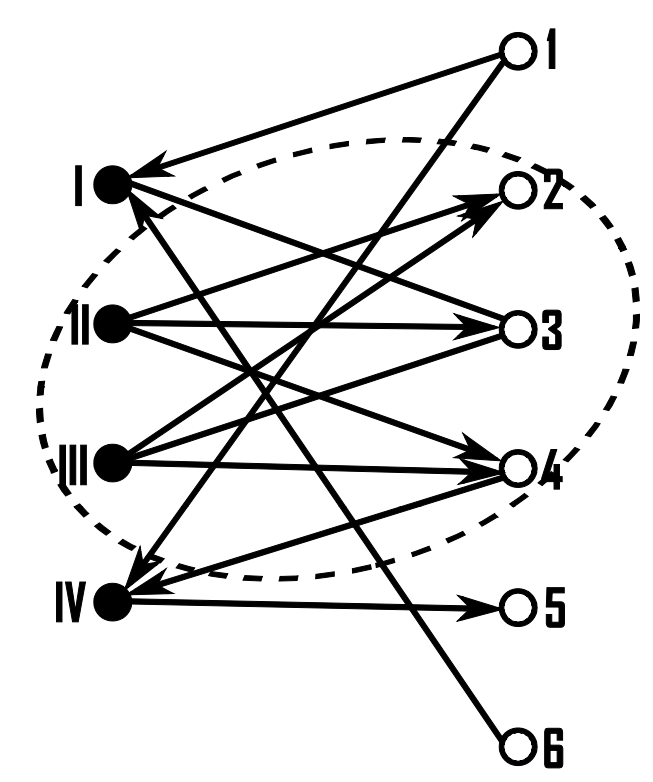

\begin{tabular}{l|c|c|c|c|c|c|}
\multicolumn{1}{c}{ I } & 2 & 3 & 4 & 5 & 6 \\
\cline { 2 - 7 } I & -1 & 0 & $X$ & 0 & 0 & -1 \\
\cline { 2 - 7 } II & 0 & 1 & 1 & 1 & 0 & 0 \\
\cline { 2 - 7 } III & 0 & 1 & $X$ & 1 & 0 & 0 \\
\cline { 2 - 7 } IV & -1 & 0 & 0 & -1 & 1 & 0 \\
\cline { 2 - 7 }
\end{tabular}




\section{Formalization of an Interaction Matrix for a Directed Bipartite Graph}

Definition 2 (Interaction matrix of a directed bipartite graph). The interaction matrix of a directed bipartite graph $G=\left(V_{1}, V_{2}, E\right)$ is defined as a $\left|V_{1}\right| \times\left|V_{2}\right|$ matrix $\mathcal{I}$ such that

$$
\mathcal{I}_{i j}=\left\{\begin{array}{l}
0, \quad \text { if }(i, j) \notin E \text { and }(j, i) \notin E \\
1, \quad \text { if }(i, j) \in E \text { and }(j, i) \notin E \\
-1, \quad \text { if }(i, j) \notin E \text { and }(j, i) \in E \\
X, \quad \text { if }(i, j) \in E \text { and }(j, i) \in E
\end{array},\right.
$$




\section{The Approach}

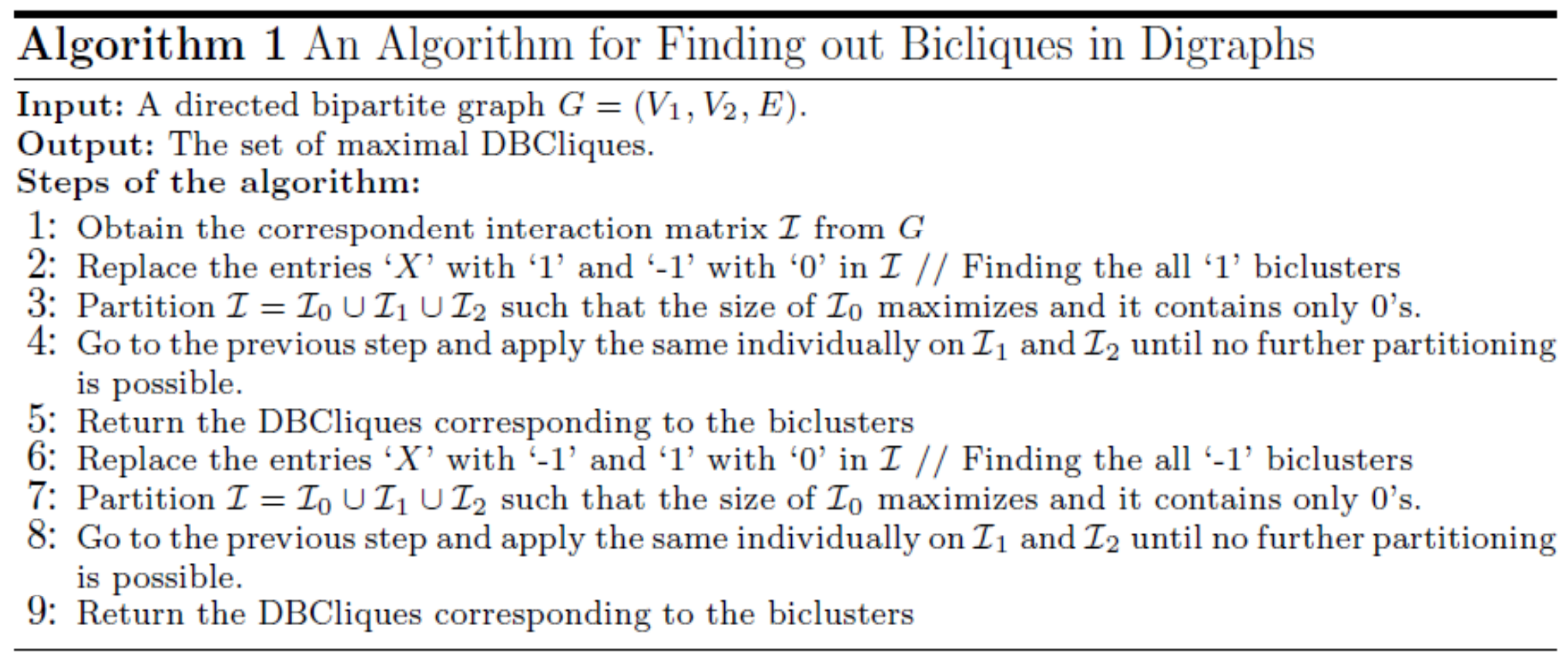




\section{Division of the Interaction Matrix}
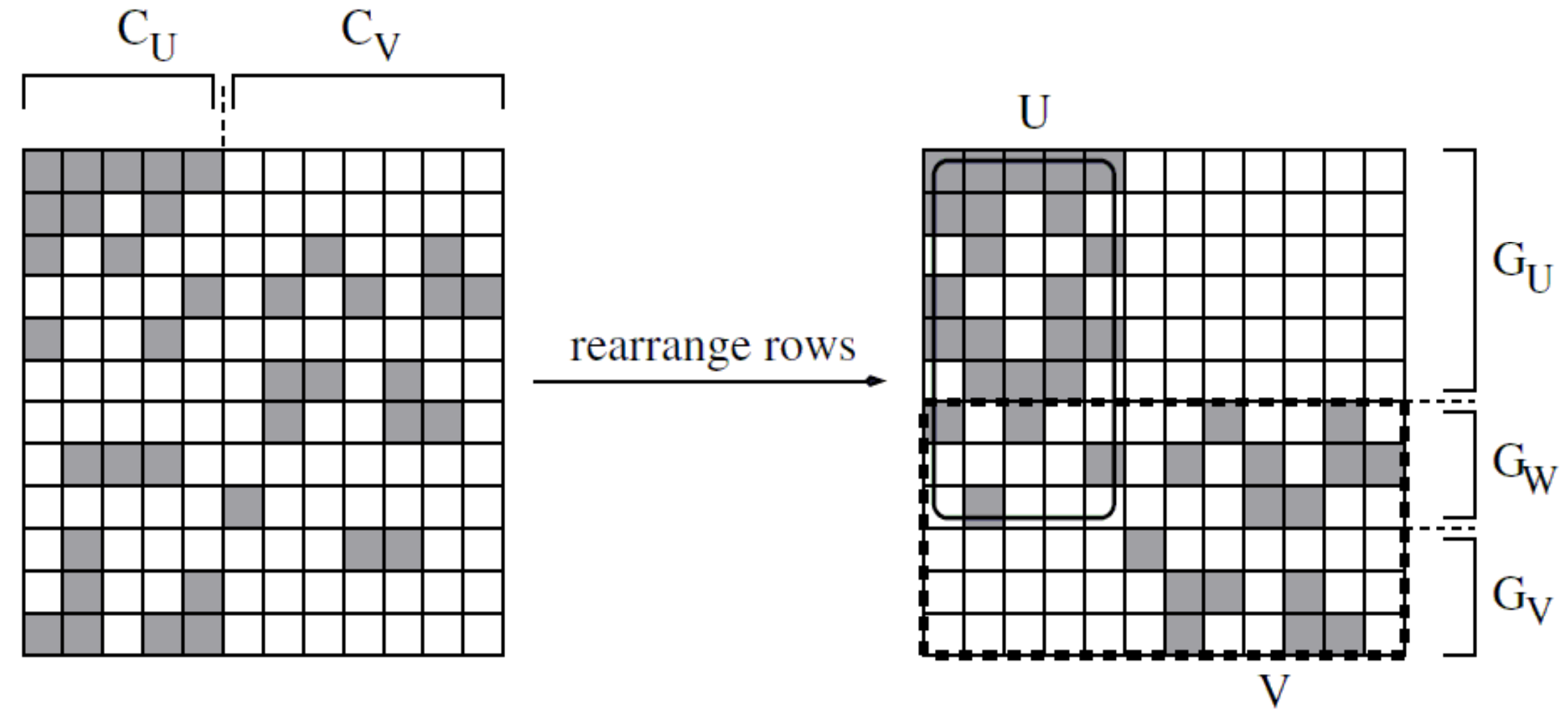

* Figure taken from [21] 


\section{Details of the Data and the DBCliques Obtained}

- Direct physical interactions/indirect interactions - categorized into 65 more specific types

- 19 HIV-1 proteins and 1448 human proteins

- 5134 interactions (18.66\% of the total possible)

Table 1. The DBCliques obtained from the HIV-1-human protein interaction network containing at least three HIV-1 and human proteins each. The size of a DBClique is defined based on the number of edges it contains.

\begin{tabular}{|c|c|c|c|}
\hline Bicluster type & Don't care allowed & \# DBCliques obtained & $\begin{array}{c}\text { Maximum size } \\
\text { (HIV-1, Human) }\end{array}$ \\
\hline \hline All ' 1 ' & Yes & 113 & $(6,5)$ \\
\hline All '-1' & Yes & 25 & $(3,13)$ \\
\hline All '1' & No & 54 & $(4,5)$ \\
\hline All '-1' & No & 7 & $(3,8)$ \\
\hline
\end{tabular}




\section{Comparative Results}

Table 2. Comparison of the largest bicliques (consisting of at least three HIV-1 and human proteins) derived by various algorithms from the HIV-1-human protein interaction network. The proposed method exclude the Don't care conditions and returns DBCliques. Crossed cells in the third column represent insignificant $p$-values.

\begin{tabular}{|c|c|c|c|c|}
\hline Analytical details & Bimax & CC & ISA & Proposed \\
\hline \hline \# Bicliques obtained & 197 & 60 & 10 & 61 \\
\hline Largest biclique found & $(4,9)$ & $(19,392)$ & $(5,76)$ & $(3,8)$ \\
\hline Best $p$-value from GO & $1.9 \mathrm{E}-6$ & $\times$ & $\times$ & $2.3 \mathrm{E}-12$ \\
\hline $\begin{array}{c}\text { Best annotation } \\
\text { (GO Term) }\end{array}$ & $\begin{array}{c}\text { Regulation of cytokinesis } \\
\text { (GO:0032465) }\end{array}$ & $\begin{array}{c}\text { Not } \\
\text { applicable }\end{array}$ & $\begin{array}{c}\text { Not } \\
\text { applicable }\end{array}$ & $\begin{array}{c}\text { Response to protein } \\
\text { stimulus (GO:0051789) }\end{array}$ \\
\hline
\end{tabular}




\section{Future Goals}




\section{Extended Regulation Including MicroRNAs}

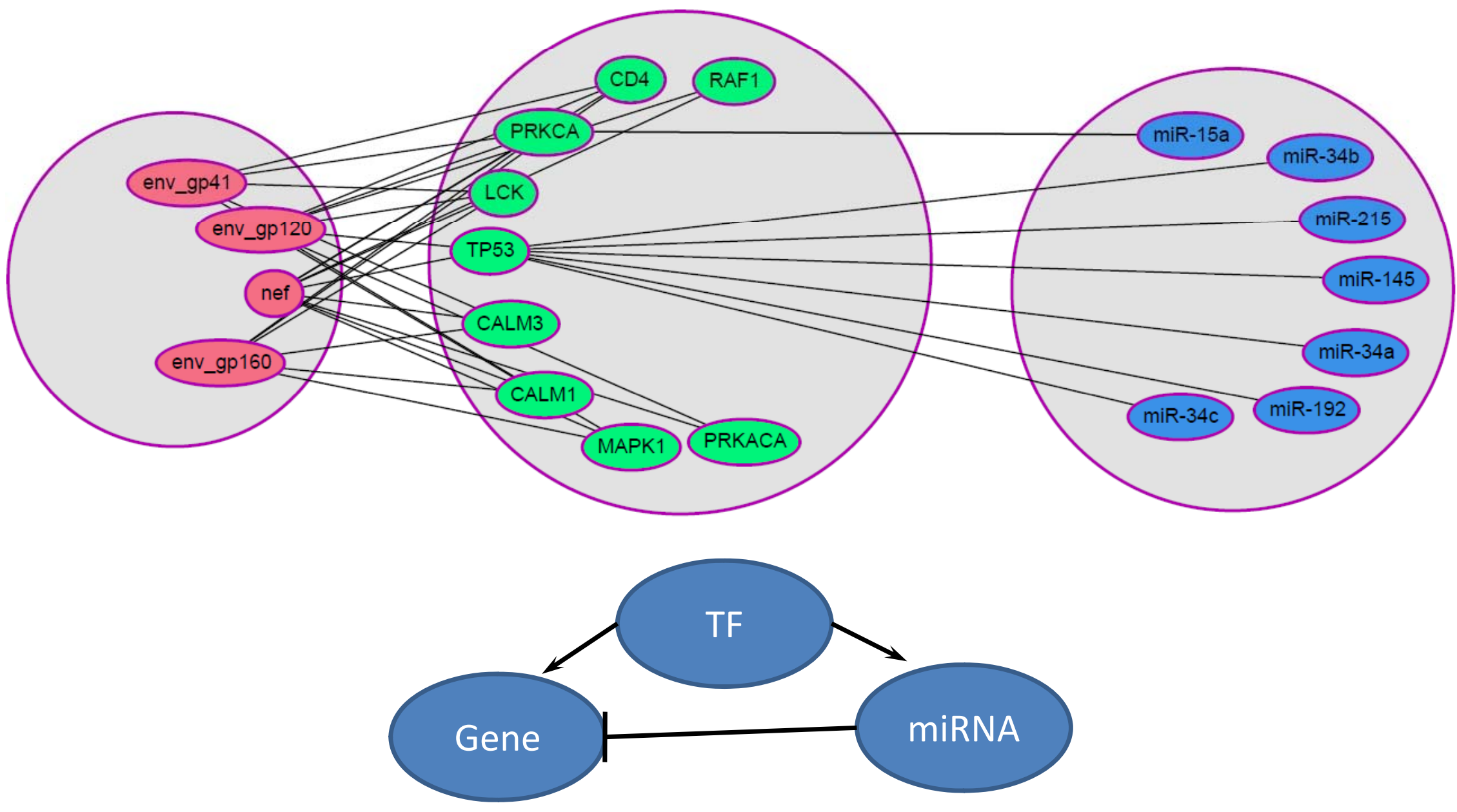




\section{Major references}

1. S. Bandyopadhyay and M. Bhattacharyya, A Biologically Inspired Measure for Coexpression Analysis, IEEE/ACM Transactions on Computational Biology and Bioinformatics, 8(4), pp. 929-942, 2011.

2. M. Bhattacharyya and S. Bandyopadhyay. Integration of Co-expression Networks for Gene Clustering. In Proceedings of the 7th International Conference on Advances in Pattern Recognition, pp. 355-358, Kolkata, India, 2009.

3. M. Bhattacharyya and S. Bandyopadhyay. Information Fusion in Bioinformatics. Technorama, The Institution of Engineers (India), Summer-Winter 2008-09:21-25, 2009.

4. S. Bandyopadhyay and M. Bhattacharyya. Mining the Largest Dense Vertexlet in a Weighted Scale-free Graph. Fundamenta Informaticae, 96(1-2):1-25, 2009.

5. M. Bhattacharyya and S. Bandyopadhyay. Analyzing Topological Properties of Proteinprotein Interaction Networks: A Perspective towards Systems Biology. In Computational Intelligence and Pattern Analysis in Biology Informatics, U. Maulik, S. Bandyopadhyay and J. T. L. Wang (Eds.), John Wiley \& Sons, Inc., pp. 349-368, 2010 (ISBN: 978-0-470-58159-9). 


\section{Major references (continued)}

6. M. Bhattacharyya and S. Bandyopadhyay. Mining the Largest Quasi-clique in Human Protein Interactome. In Proceedings of the International Conference on Adaptive and Intelligent Systems, pp. 194-199, Klagenfurt, Austria, 2009.

7. M. Bhattacharyya and S. Bandyopadhyay. A Combinatorial Counterpart of the Maximum Quasi-clique Problem. In Proceedings of the International Conference on Discrete Mathematics, Algebra and their Applications, pp. 129-130, Minsk, Belarus, 2009.

8. M. Bhattacharyya and S. Bandyopadhyay, Solving Maximum Fuzzy Clique Problem with Neural Networks and its Applications, Memetic Computing, Thematic Issue on "Adaptive Soft Computing Techniques and Applications", 1(4), pp. 281-290, 2009.

9. S. Bandyopadhyay and M. Bhattacharyya. A Chaotic Neuro-GA Synergism for Solving Maximum Fuzzy Clique Problem, In Proceedings of the 15th International Conference on Neural Information Processing, Auckland, New Zealand, November 25-28, pp. 209-210, 2008.

10. S. Bandyopadhyay and M. Bhattacharyya. Analyzing miRNA co-expression networks to explore TF-miRNA regulation. BMC Bioinformatics, 10:163, 2009. 


\section{Major references (continued)}

11. S. Bandyopadhyay and M. Bhattacharyya. PuTmiR: A database for extracting neighboring transcription factors of human microRNAs. BMC Bioinformatics, 11:190, 2010.

12. M. Bhattacharyya and S. Bandyopadhyay. Computational Discovery of Different Categories of Human Oncogenic MicroRNAs. In Proceedings of the 1st IFIP International Conference on Bioinformatics, no. 94, Surat, India, 2010.

13. S. Bandyopadhyay and M. Bhattacharyya. A Novel Method of Studying the Disease Regulatory Activities of MicroRNAs. Current Bioinformatics, 4(3):234-241, 2009.

14. M. Bhattacharyya, S. Bandyopadhyay and U. Maulik, Finding Bicliques in Digraphs: Application into Viral-host Protein Interactome, In Proceedings of the 4th International Conference on Pattern Recognition and Machine Intelligence, Moscow, Russia, June 27-July 01, Springer LNCS 6744, pp. 412-417, 2011.

15. M. Bhattacharyya and S. Bandyopadhyay, Co-expression Toggling of MicroRNAs in Alzheimer's Brain, SiNAPSA Neuroscience Conference, Ljubljana, Slovenia, 2011.

16. U. Maulik, M. Bhattacharyya, A. Mukhopadhyay, S. Bandyopadhyay, Identifying the Immunodeficiency Gateway Proteins in Human and their Involvement in MicroRNA Regulation, Molecular Biosystems, 7(6), pp. 1842-1851, 2011. 


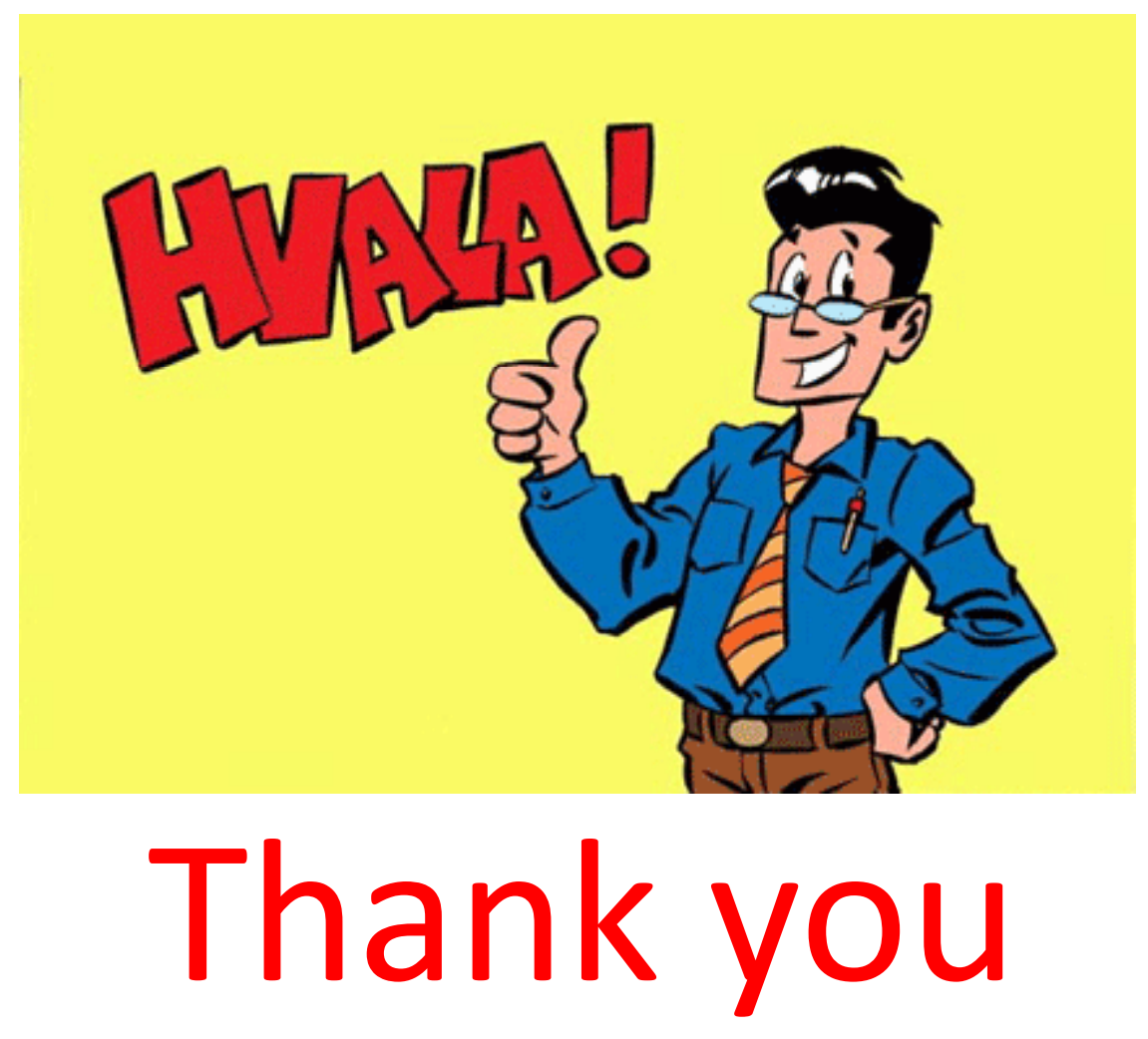

